\title{
Voluntary enhancement of penile erection
}

\author{
H. B. RUBIN \\ Southern Illinois University, Carbondale, Illinois b2901 \\ and \\ DONALD E. HENSON \\ Anna State Hospital, Anna, Ilinois 62906
}

\begin{abstract}
Six human male subjects developed moderate to high sexual arousal, as measured by a penile transducer, to an erotic film and, in the absence of overt erotic stimulation, to erotic fantasy. When instructed to enhance their arousal to the film without employing any physical stimulation, four of the six subjects were able to significantly increase their erections above the levels that were produced by either the film or the fantasy alone. The remaining two subjects, however, responded in an opposite manner in that the instructions to enhance arousal resulted in a decrease of their erections to a level below that produced by either the film or the fantasy alone. These data indicate that although attempts to voluntarily control sexual arousal may be distracting to some men, they are effective for others.
\end{abstract}

Penile tumescence is generally considered to be an involuntary or reflex reaction to erotic stimulation (Houssay, 1955; Masters \& Johnson, 1966, 1970: Weiss. 1972). Masters and Johnson (1970) have characterized the reflexive nature of erection as follows: "Attainment of an erection is something over which he has no voluntary control ... no man can will, wish or demand an erection" (p. 11).

However, recent studies have indicated that normal males do have some control over their erectile responses. For example, when college-age men were instructed to inhibit their arousal to an erotic stimulus, every one responded with considerably less tumescence than when not under such instructions (Laws \& Rubin, 1969). When given feedback about the state of their arousal, the ability to suppress erections was improved (Rosen, 1973), and the ability continued even when the preferred means for inhibiting (concentrating on asexual stimuli) was eliminated (Henson \& Rubin, 1971).

Control is not limited to inhibition of erections; it has been demonstrated that men can produce erections in the absence of overt erotic stimuli, including penile manipulation, by merely thinking sexual thoughts (Bancroft \& Mathews, 1971; Laws \& Rubin, 1969). But, does the ability to produce arousal imply an ability to make an erotic situation more arousing? Although some data would suggest that men may attempt to enhance their arousal during masturbation (Kinsey, Pomeroy, \&

The authorship of this paper is considered equal. Donald E. Henson is presently at Southern Illinois University, Carbondale, Illinois 62901. This research was supported by grants from the Mental Health Fund of the Illinois Department of Mental Health and NIMH Grant 04925 . Reprints may be obtained from H. B. Rubin. School of Medicine, Southern Illinois University, Carbondale. Illinois 62901.
Martin, 1948) or even coitus (Athanasiou, Shaver, \& Tavris, 1970) by engaging in erotic fantasy, there are no data that indicate whether such attempts are effective.

\section{METHOD}

Subjects

Six adult male volunteers (age 22-28 years) who were fully informed of the nature of the experiment served as subjects for no remuneration; S 4 and $S 5$ had previous exposure to the experimental environment and four were experimentally naive.

\section{Procedure}

The procedure was similar to that of Laws and Rubin (1969) and Henson and Rubin (1971) - - that is, a modified version of the mercury-in-rubber strain gauge transducer developed by Bancroft, Jones, and Pullan (1966) was used to continuously measure changes in penile circumference (for full description see Laws \& Rubin, 1969). The transducer was calibrated before and after each session by placing the loop around different-sized cylinders. The erotic stimulus, a black and white motion picture (about $11 \mathrm{~min}$ ) that depicted a variety of heterosexual activities, was displayed by video tape equipment onto a TV monitor located in a private sound-attenuated experimental room. To ensure that subjects attended to the area of film presentation, the signal detection procedure of Laws and Rubin (1969) was employed, i.e., the subjects were required to respond to brief flashes of light projected on the monitor screen.

Penile flaccidity was individually defined as the circumference recorded when penile size stabilized (less than $2.5 \%$ of full scale variability for at least $30 \mathrm{sec}$ ). Full erection was individually defined as the maximum penile circumference recorded for each subject who reported experiencing a full erection to the erotic stimuli (or, in the case of $S 4$, to an earlier recorded exposure to another stimulus film) and whose penile response pattern was characteristic of full erection, i.e., a short latency to a comparatively large, generally smooth and regular, maximum pen deflection (Laws \& Rubin, 1969). For S 2, an empirical determination of full tumescence was not possible; therefore, his "full" erection was estimated using the mean increase in circumference from flaccidity to full erection recorded for other 


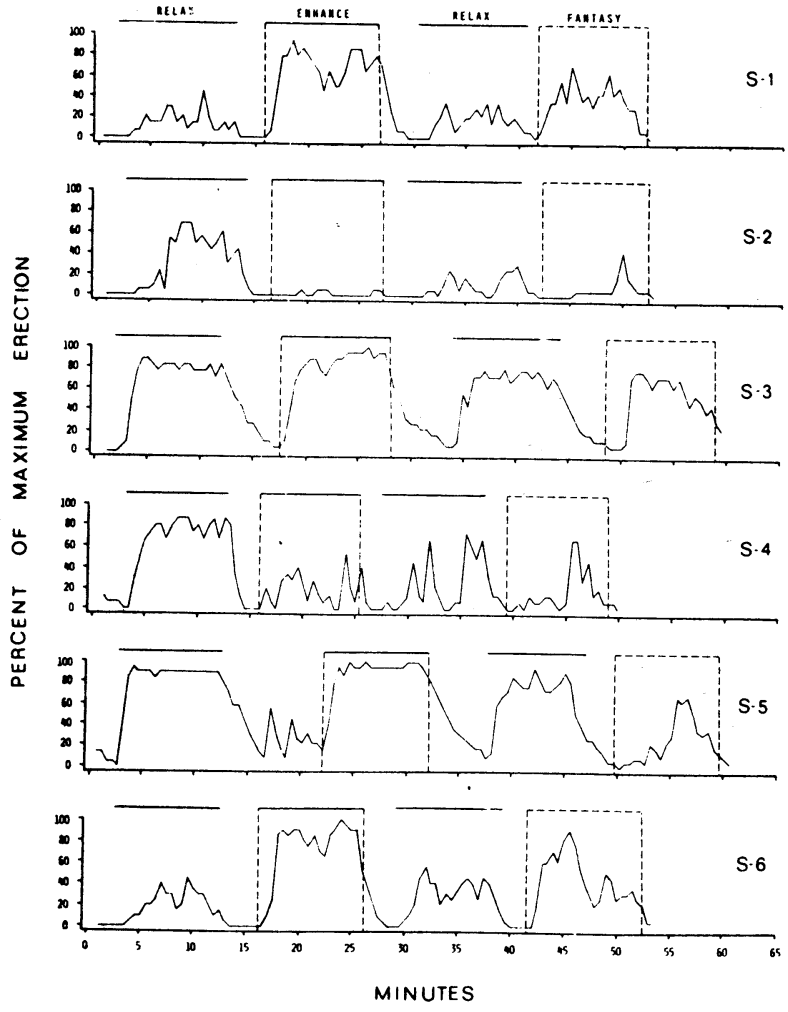

Figure 1. Amount of penile erection developed by six subjects during four successive erotic conditions.

subjects as the range of his response. Full erections were reported as $100 \%$, flaccidity as $0 \%$, and partial erections as a percentage of full erections.

The experiment was comprised of three successive presentations of the erotic film followed by a 10 -min period of no film presentation. Each subject was instructed, via an intercom, to relax and enjoy the film during Film Presentations 1 and 3 (relax condition), to enhance his sexual arousal by any means except physical stimulation of the penis, which could be detected by spikes in the recording, during Film Presentation 2 (enhance condition), and to become sexually aroused by any means except physical stimulation of the penis during the period when no film was presented (fantasy condition). The criterion for the onset of the first relax condition was at least $30 \mathrm{sec}$ of penile stability in the flaccid state, and subsequent conditions began after the penis returned to within $5 \%$ of flaccidity and remained stable for $30 \mathrm{sec}$. However, on two occasions, S 5 did not return to this baseline, and a new condition was presented to him after at least a 5-min interval and $30 \mathrm{sec}$ of stability. Subjects did not remove the transducer or leave the chamber for the duration of the experiment.

\section{RESULTS}

There was no variation in within-session calibrations of the transducer except for $\mathrm{S} 6$, and that difference did not exceed $2.5 \%$ of full scale variability and affected only the baseline, not the range of responding. There also was no systematic variation between conditions in the percentage of signal lights detected.

As can be seen in Figure 1, which shows the amount of penile erection developed by each subject during each condition, subjects were separated into two categories with respect to their ability to comply with the instructions to enhance their arousal. Thus, under the enhance condition, S $1, S 3, S 5$, and S 6 produced their largest peak erection (which for them was full erection), greatest mean erection, and shortest latency to $20 \%$ of maximum erection for the experiment. Two of these subjects markedly enhanced their erections. The other two increased their erections by a much smaller amount, apparently because the film elicited nearly full erections from them, but each spent more than $50 \%$ of the enhance condition with an erection that exceeded the peak elicited during the relax conditions. A one-tailed $t$ test for dependent measures analysis indicated that their peak erections in the enhance condition were significantly larger than during the baseline condition, i.e., the mean of both relax instructional conditions, $t(3)=2.53, p<.05$, and the fantasy condition, $\mathrm{t}(3)=5.77, \mathrm{p}<.01$. Their mean erections for the enhance condition were also significantly larger than during baseline, $\mathrm{t}(3)=2.91, \mathrm{p}<.05$, and fantasy conditions, $t(3)=4.15, p<.05$. However, the latency measure during the enhance condition was not significantly shortened compared to either the baseline or fantasy conditions. The other two subjects did not enhance their arousal to the film and, in fact, produced their smallest peak and mean erections and longest latencies to $20 \%$ of maximum for the experiment, but only the peak erection was significantly reduced compared to baseline, $\mathrm{t}(1)=7.10, \mathrm{p}<.05$.

\section{DISCUSSION}

Every subject reportedly attempted to voluntarily enhance his arousal to the erotic film by means of erotic fantasy, regardless of the outcome of such activity. The degree of arousal attained during the fantasy condition, however, appeared to be somewhat related to the effect that resulted from the admixture of film and fantasy. The four who enhanced their arousal developed more tumescence and three of four had shorter arousal latencies than did either of the no-enhance subjects, but the differences were small.

The disruption in sexual performance experienced by the no-enhance subjects when instructed to become more aroused is congruent with the premise stated by Masters and Johnson (1970) that "no man can will an erection" and that "the only thing accomplished by such attempts is blocking of sensate (erotic) input" (p. 202). This interpretation of the data is supported by the fact that both of these subjects became more aroused when responding either to the film alone or to the fantasy alone than to the two combined.

The ability of the other subjects to comply with instructions to increase their arousal, however, indicates that covert mental activity does not always detract from sexual arousal. They apparently could integrate self-generated erotic stimuli with the stimuli present in the environment to produce a more arousing situation. This is probably analogous to what occurs when men fantasize as they masturbate and may be why many men, including four of the six subjects in the present study, report that they imagine at least occasionally that their sex partner is someone else (Athanasiou et al., 1970). However, the subjects who enhanced during this study did not report any more use of fantasy during coitus than the no-enhance subjects. 
Since the occurrence of erotic fantasy is a private, unobservable activity that is primarily self-regulated, it appears reasonable to characterize fantasy as a method by which males attempt to exert voluntary control over the development of sexual arousal. Moreover, the possibility exists that the obtained results might be specific to the environmental situation in which the male attempts to enhance his arousal. For example, the subjects who were unable to voluntarily produce more arousal in the laboratory perhaps could do so during masturbation or coition in a more natural environment. Or, conversely, perhaps subjects who demonstrated an ability to increase their arousal would be unable to do so under instructional or environmental conditions construed as demanding. What is unequivocal, however, is that some males under some conditions can voluntarily enhance their penile tumescence to overt erotic stimuli apparently by means of fantasy.

There are several reports (e.g., Davison, 1968; Marquis, 1970) of the use of erotic fantasy to condition arousal to appropriate sexual stimuli as a therapeutic approach to sexual deviancy; the general paradigm is to substitute a heterosexual fantasy for a deviant fantasy during masturbation. Kaplan (1974) has reported that instructions to employ masturbatory fantasy during physical stimulation resulted in successful therapy for impotence and ejaculatory incompetence. In that context, fantasy was characterized as a means by which the dysfunctional male could distract himself from the anxiety-inducing stimuli that were interfering with his sexual arousal. The present data, however, suggest that the erotic fantasy might have a direct enhancement effect. Regardless of how its action is formulated, such voluntary activity does not necessarily detract from sexual arousal, and thus the value of incorporating erotic fantasy into the therapeutic paradigm should not be discounted.

\section{REFERENCES}

Athanasiol: R., Shaver, P., \& Tavris, C. Sex. Psichology Toduy. 1970, 4, 37-52.
Bancroft, J. H. J., Jones, H. C., \& Pullan, B. R. A simple transducer for measuring penile erection with comments on its use in treatment of sexual disorders. Behaviour Research and Therapy, 1966, 4, 239-242.

Bancroft, J. H. J., \& Mathews, A. M. Autonomic correlates of penile erection. Journal of Psychosomatic Research, 1971, 15, 159-167.

Davison, G. Elimination of a sadistic fantasy by clientcontrolled counterconditioning technique. Journal of Abnormal Psychology, 1968, 73, 84-90.

Henson, D. E., \& Rubin, H. B. Voluntary control of eroticism. Journal of Applied Behavior Analysis, 1971, 4. 37-44.

Houssay, B. A. Human physiology. New York: McGraw-Hill, 1955.

Kaplan. H. S. The new sex therapy: Active treatment of sexual dysfunctions. New York: Brunner/Mazel, 1974.

Kinsey, A. C., Pomeroy, W. B., \& Martin, C. E. Sexual behavior in the human male. Philadelphia: Saunders, 1948.

LAws, D. R., \& RuBin, H. B. Instructional control of an autonomic sexual response. Journal of Applied Behavior Analysis, 1969, 2, 93-99.

MARQuis, J. N. Orgasmic reconditioning: Changing sexual object choice through controlling masturbatory fantasies. Journal of Behavior Therapy and Experimental Psychiatry, 1970, i, 26.3-271.

Masters, W. H., \& Johnson, V. E. Human sexual response. Boston: Little-Brown, 1966

Masters. W. H.. d Johnson, V. E. Human sexual inadequacy. Boston: Little-Brown, 1970.

ROSEn. R. C. Suppression of penile tumescence by instrumental conditioning. Psychosomatic Medicine, 1973, 35, 509-514.

WeIsS, H. D. The physiology of human penile erection Annals of Internal Medicine, 1972, 76, 793-799.

(Received for publication May 21, 1975.) 